\title{
Microbial Production of Bioactive Retinoic Acid Using Metabolically Engineered Escherichia coli
}

\author{
Minjae Han (D) and Pyung Cheon Lee*(D) \\ Department of Molecular Science and Technology, Ajou University, World Cup-ro, Yeongtong-gu, \\ Suwon-si 16499, Gyeonggi-do, Korea; oneminzaeh@ajou.ac.kr \\ * Correspondence: pclee@ajou.ac.kr; Tel.: +82-31-219-2461
}

Citation: Han, M.; Lee, P.C. Microbial Production of Bioactive Retinoic Acid Using Metabolically Engineered Escherichia coli. Microorganisms 2021, 9, 1520. https://doi.org/10.3390/ microorganisms 9071520

Academic Editors: Sachiyo Aburatani, Hiroaki Takaku and Tomokazu Shirai

Received: 12 June 2021

Accepted: 14 July 2021

Published: 16 July 2021

Publisher's Note: MDPI stays neutral with regard to jurisdictional claims in published maps and institutional affiliations.

Copyright: (c) 2021 by the authors. Licensee MDPI, Basel, Switzerland. This article is an open access article distributed under the terms and conditions of the Creative Commons Attribution (CC BY) license (https:// creativecommons.org/licenses/by/ $4.0 /)$.

\begin{abstract}
Microbial production of bioactive retinoids, including retinol and retinyl esters, has been successfully reported. Previously, there are no reports on the microbial biosynthesis of retinoic acid. Two genes $\left(b l h_{S R}\right.$ and $\left.r a l d h_{H S}\right)$ encoding retinoic acid biosynthesis enzymes [ $\beta$-carotene 15,15'-oxygenase (Blh) and retinaldehyde dehydrogenase2 (RALDH2)] were synthetically redesigned for modular expression. Co-expression of the $b h_{S R}$ and $r a l d h_{H S}$ genes on the plasmid system in an engineered $\beta$-carotene-producing Escherichia coli strain produced $0.59 \pm 0.06 \mathrm{mg} / \mathrm{L}$ of retinoic acid after flask cultivation. Deletion of the $y b b O$ gene encoding a promiscuous aldehyde reductase induced a 2.4-fold increase in retinoic acid production to $1.43 \pm 0.06 \mathrm{mg} / \mathrm{L}$. Engineering of the 5'-UTR sequence of the $b h_{S R}$ and $r a l d h_{H S}$ genes enhanced retinoic acid production to $3.46 \pm 0.16 \mathrm{mg} / \mathrm{L}$. A batch culture operated at $37{ }^{\circ} \mathrm{C}, \mathrm{pH} 7.0$, and $50 \%$ DO produced up to $8.20 \pm 0.05 \mathrm{mg} / \mathrm{L}$ retinoic acid in a bioreactor. As the construction and culture of retinoic acid-producing bacterial strains are still at an early stage in the development, further optimization of the expression level of the retinoic acid pathway genes, protein engineering of Blh and RALDH2, and culture optimization should synergistically increase the current titer of retinoic acid in E. coli.
\end{abstract}

Keywords: retinoid; retinoic acid; metabolic engineering; retinaldehyde dehydrogenase; $\beta$-carotene $15,15^{\prime}$-oxygenase

\section{Introduction}

Retinoids (or vitamin A and its analogs) are essential components of visual function, cell differentiation, and other cellular signaling pathways [1,2]. Retinoids are lipophilic compounds with diverse structures, based on their end groups. They are composed of three structural moieties: a $\beta$-ionone ring, an isoprenoid backbone, and a functional group such as an alcohol (retinol), an aldehyde (retinal), a carboxylic acid (retinoic acid), or an ester group (retinyl esters) [3]. In a biotechnological aspect, retinoids are used as a dermatological agent against acne, psoriasis, skin aging, and other skin conditions [4].

Retinoic acid is one of the most important ingredients in cosmetic skincare products because it can protect against UV-radiation-induced skin damage in fibroblasts and other skin cells [5]. Therefore, there is a high demand for retinoic acid in the cosmetic and pharmaceutical industries [6]. In a biological system, retinoic acid is biosynthesized from $\beta$-carotene in two reaction steps (Figure 1 ). $\beta$-carotene is symmetrically cleaved by $\beta$-carotene $15,15^{\prime}$-oxygenase (Blh), generating retinaldehyde (also known as retinal), which is then oxidized to retinoic acid by retinal dehydrogenase (Raldh). The retinoic acid precursor $\beta$-carotene is synthesized by four biosynthetic pathway enzymes [7], known as geranylgeranyl diphosphate synthase $(\mathrm{CrtE})$, phytoene synthase $(\mathrm{CrtB})$, phytoene desaturase (CrtI), and lycopene cyclase (CrtY) (Figure 1).

Most retinoic acids are commercially produced via chemical synthesis [8]. Microbial production of RA has received attention as an alternative process for retinoic acid. Although retinol and retinyl ester have been produced in microbial host strains, including 
Escherichia coli [9-11] and Saccharomyces cerevisiae [12], there are no reports on the microbial biosynthesis of retinoic acid. As E. coli has been exploited as a microbial host system for retinoid production, it can serve as a host for the redesign and reconstruction of the retinoic acid pathway.

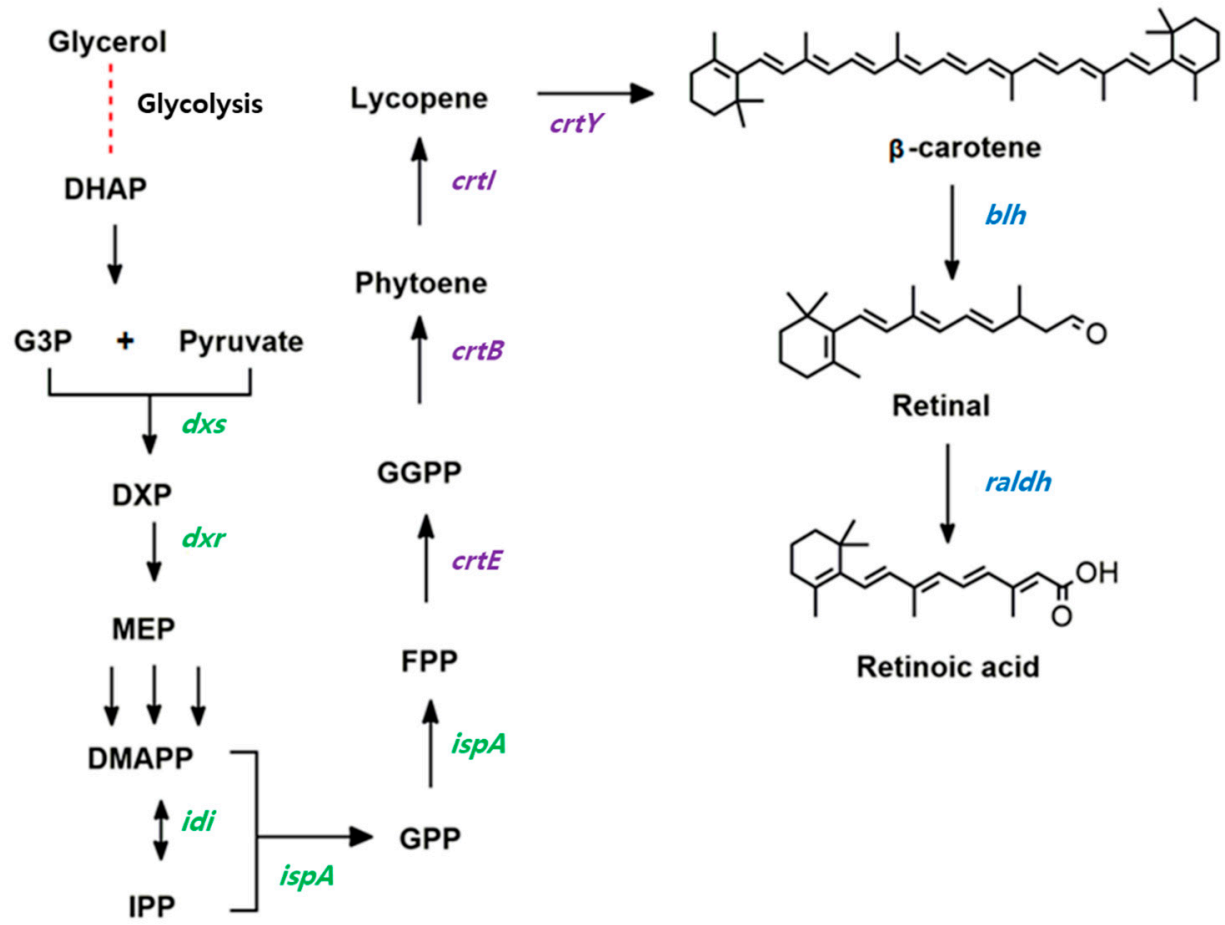

Figure 1. Redesigned biosynthetic pathway of retinoic acid from $\beta$-carotene in recombinant Escherichia coli. The genes involved in this redesigned pathway are $d x s$ (encoding1-deoxy-D-xylulose5-phosphate synthase); $d x r$ (1-deoxy-D-xylulose-5-phosphate reductoisomerase); idi (isopentenyl diphosphate isomerase); ispA (farnesyl diphosphate synthase); $c r t E$ (geranylgeranyl diphosphate synthase); $\operatorname{crtB}$ (phytoene synthase); $\operatorname{crtI}$ (phytoene desaturase); crtY (lycopene cyclase); blh ( $\beta$-carotene 15,15'-oxygenase); and raldh (retinal dehydrogenase).

In this study, the retinoic acid biosynthesis pathway was reconstructed by co-expressing Blh from Salinibacter ruber and Raldh from the Hep3B cell line in a metabolically engineered $\beta$-carotene-producing E. coli. Next, retinoic acid titer was enhanced by deleting a gene encoding a promiscuous enzyme which reduced retinoic acid titer, engineering of the 5 '-UTR sequence of the two retinoic acid pathway genes, and optimization of the culture conditions of a retinoic acid-producing strain in a bioreactor.

\section{Materials and Methods}

\subsection{Strains, Media, and Culture Conditions}

All E. coli strains and plasmids used in this study are listed in Table 1. The E. coli Top 10 strain was used for gene cloning, and E. coli BL21(DE3) was used for protein expression. The E. coli strains were grown in Luria-Bertani (LB) broth $(10 \mathrm{~g} / \mathrm{L}$ tryptone, $5 \mathrm{~g} / \mathrm{L}$ yeast extract, and $5 \mathrm{~g} / \mathrm{L} \mathrm{NaCl}$ ) at $37{ }^{\circ} \mathrm{C}$ with shaking at $250 \mathrm{rpm}$. For retinoid production, the E. coli MG1655 strain was grown in Terrific Broth (TB) medium (12 g/L of tryptone, $24 \mathrm{~g} / \mathrm{L}$ of yeast extract, $0.17 \mathrm{M} \mathrm{KH}_{2} \mathrm{PO}_{4}$, and $0.72 \mathrm{M} \mathrm{K}_{2} \mathrm{HPO}_{4}$ ) supplemented with $20 \mathrm{~g} / \mathrm{L}$ of glycerol on a rotary shaker at $30^{\circ} \mathrm{C}$ and $250 \mathrm{rpm}$. The Hep3B cell line was a gift from Professor Wook Kim (Ajou University, Suwon, Korea). 
Table 1. Strains and plasmids used in this study.

\begin{tabular}{|c|c|c|}
\hline Strains and Plasmids & Relevant Properties & $\begin{array}{l}\text { Source or } \\
\text { Reference }\end{array}$ \\
\hline \multicolumn{3}{|l|}{ Strains } \\
\hline E. coli TOP10 & $\begin{array}{l}\text { F- mcrA } \Delta \varphi 80 \text { lacZ } \Delta \text { M15 } \Delta \text { lacX74 nupG recA1 araD139 } \Delta \text { (ara-leu)7697 } \\
\text { galE15 galK16 rpsL }\left(\operatorname{Str}^{\mathrm{R}}\right) \text { endA1 }\end{array}$ & Invitrogen \\
\hline E. coli BL21(DE3) & $\begin{array}{l}\mathrm{F}^{-} \text {omp Tgaldcmlonhsd } \mathrm{S}_{\mathrm{B}}\left(r_{B}{ }^{-} m_{B}{ }^{-}\right) \lambda(\mathrm{DE} 3 \text { [lacIlacUV5-T7p07 ind1 sam7 nin5]) } \\
{\left[\text { malB }^{+}\right]_{\mathrm{K}-12}\left(\lambda^{\mathrm{S}}\right)}\end{array}$ & NEB \\
\hline BETA-1 & B120 ::idi ::ispA :: dxs :: dxr :: CrtEX2 :: Ptrc_YIB_PAG (atpI site) & unpublished \\
\hline BETA- $1 \Delta y b b O$ & Deletion of $y b b O$ in BETA- 1 & This study \\
\hline BETA- $1 \Delta$ ybbO $\Delta$ malT::37blh & Integration of UTR37-blh in BETA- $1 \Delta y b b O$ & This study \\
\hline BETA-1 $\Delta$ ybbO $\Delta$ malT:: Mraldh & Integration of UTRM-raldh in BETA- $1 \Delta y b b O$ & This study \\
\hline BETA-1 $\Delta$ ybbO $\Delta$ malT::37blh::Mraldh & Integration of UTR37-blh and UTRM-raldh in BETA- $1 \Delta y b b O$ & This study \\
\hline \multirow{2}{*}{\multicolumn{3}{|c|}{$\begin{array}{l}\text { Plasmids for pathway construction } \\
\text { pUCM }\end{array}$}} \\
\hline & Cloning vector modified from pUC19; constitutive lac promoter, Ap & \\
\hline pUCMr & $\begin{array}{l}\text { Cloning vector modified from pUCM; constitutive lac promoter and rop } \\
\text { gene, Ap (low copy plasmid) }\end{array}$ & [11] \\
\hline pSTVM2 & Cloning vector modified from pSTV29; constitutive lac promoter, $\mathrm{Cm}$ & \\
\hline pUCMr-blh & Constitutive expressed blh gene from S. ruber & [11] \\
\hline pUCMr12-blh & Constitutive expressed blh gene from $S$. ruber with UTR12 sequence & [11] \\
\hline pUCMr37-blh & Constitutive expressed $b l h$ gene from $S$. ruber with UTR37 sequence & {$[11]$} \\
\hline pUCMr46-blh & Constitutive expressed blh gene from $S$. ruber with UTR46 sequence & [11] \\
\hline pUCMr-raldh & Constitutive expressed raldh gene from Hep3B cell line & This study \\
\hline pUCMrH-raldh & Constitutive expressed raldh gene from Hep3B cell line with UTRH sequence & This study \\
\hline pUCMrM-raldh & $\begin{array}{l}\text { Constitutive expressed raldh gene from Hep3B cell line with UTRM } \\
\text { sequence }\end{array}$ & This study \\
\hline pSTVM2-blh-raldh & Constitutive expressed blh and raldh genes & This study \\
\hline pSTVM2-37blh & Constitutive expressed UTR37-blh gene & This study \\
\hline pSTVM2-Mraldh & Constitutive expressed UTRM- raldh gene & This study \\
\hline pSTVM2-12blh-raldh & Constitutive expressed UTR12-blh gene and raldh gene & This study \\
\hline pSTVM2-37blh-raldh & Constitutive expressed UTR37-blh gene and raldh gene & This study \\
\hline pSTVM2-46blh-raldh & Constitutive expressed UTR46-blh gene and raldh gene & This study \\
\hline pSTVM2-blh-Hraldh & Constitutive expressed blh gene and UTRH-raldh gene & This study \\
\hline pSTVM2-blh-Mraldh & Constitutive expressed blh gene and UTRM-raldh gene & This study \\
\hline pSTVM2-37blh-Hraldh & Constitutive expressed UTR37-blh gene and UTRH-raldh gene & This study \\
\hline pSTVM2-37blh-Mraldh & Constitutive expressed UTR37-blh gene and UTRM-raldh gene & This study \\
\hline Plasmids for western botting & & This study \\
\hline pET21 $\alpha(+)$ & Inducible expression vector, $\mathrm{Ap}$ & Novagen \\
\hline pET21-blh & Induciblyl expressed $6 \times$ His-tagged blh gene in pET $21 \alpha(+)$ & This study \\
\hline pET21-raldh & Induciblyl expressed $6 \times$ His-tagged raldh gene in pET21 $\alpha(+)$ & This study \\
\hline Plasmids for genome editing & & This study \\
\hline $\mathrm{pRed} / \mathrm{ET}$ & Inducible expression Red/ET, Ap & $\begin{array}{l}\text { Gene } \\
\text { Bridge }\end{array}$ \\
\hline pMP11 & $\begin{array}{l}\text { pKD46 with constitutively expressed Cas9,aTc gRNA targeting ColE1 } \\
\text { origin }\end{array}$ & {$[13]$} \\
\hline pgRNA & Constitutively expressed sgRNA & [13] \\
\hline pgRNA_malT & Constitutively expressed sgRNA targeting malT & This study \\
\hline
\end{tabular}

\subsection{Plasmid Construction for the Expression of Retinoid Biosynthesis Pathway Enzymes}

The $b l h_{S R}$ gene encoding $\beta$-carotene 15,15'-oxygenase (BlhSR) from S. ruber, which was previously cloned in the plasmid pUCMr-blh [11], was utilized, and the $r a l d h_{H S}$ gene encoding retinaldehyde dehydrogenase 2 (RALDH2, GenBank accession number, AB015226.1) from the Hep3B cell line was cloned into pUCMr to construct pUCMr-raldh (Table 1). To construct the retinoic acid pathway, the two genes encoding BlhSR and RALDH2 were redesigned as an individual expression module, and then assembled into the plasmid pSTVM2, using the USER ${ }^{\circledR}$ cloning method, resulting in pSTVM2-blh-raldh.

To enhance the expression levels of the two genes in E. coli, the $5^{\prime}$-untranslated regions (5'-UTRs) of the two genes were engineered by using 26-bp mRNA-stabilizing sequences, 
which were obtained by using UTR designer (http:/ / sbi.postech.ac.kr/utr_designer, accessed on 7 May 2020). Three 5'-UTRs of blhSR (UTR12, UTR37, and UTR46), which were investigated in our previous study [11], were utilized as pUCMr12-blh, pUCMr37-blh, and pUCMr46-blh, respectively, in this study. In a similar way described in [11], two 5'-UTRs of RALDH2 (named UTRH for high expression, and UTRM for moderate expression) were predicted using UTR designer, and two plasmids (pUCMrH-raldh and pUCMrMraldh) were constructed. Next, the two genes with corresponding $5^{\prime}$-UTR sequences were subcloned into pSTVM2, using Gibson assembly [3], resulting in pSTVM2-12blh-raldh, pSTVM2-37blh-raldh, pSTVM2-46blh-raldh, pSTVM2-blh-Hraldh, pSTVM2-blh-Mraldh, pSTVM2-37blh-Hraldh, and pSTVM2-37blh-Mraldh (Table 1).

\subsection{Deletion of the ybbO Gene in the BETA-1 Strain}

The $y b b O$ gene, which encodes a putative oxidoreductase in the BETA- 1 strain, was deleted through one-step homologous recombination, using the pRed/ET-mediated recombination method (Gene Bridges, Heidelberg, Germany). A ybbO-deleting linear DNA fragment consisting of a 50-bp left homology arm sequence, a FRT- $\mathrm{Km}^{\mathrm{r}}$-cassette, and a 50-bp right homology arm sequence was constructed by using the USER cloning kit (New England Biobabs, Ipswich, MA, USA) with specific primers (Supplementary Materials Table S1). The $y b b O$-deletion mutants were selected on LB agar plates containing $30 \mu \mathrm{g} / \mathrm{mL}$ kanamycin, followed by the generation of a $\mathrm{Km}^{\mathrm{R}}$ marker-free strain, using an FLP recombinase, which was inducibly expressed in the temperature-sensitive pCP20 helper plasmid. The sequence of the deletion site in the BETA-1 strain was verified via Sanger sequencing of the isolated gDNA. The resultant $y b b O$-deletion strain was named BETA-1 $\triangle \mathrm{ybbO}$.

\subsection{Integrating Two Retinoic Acid Pathway Genes into the BETA-1 $\triangle y b b O$ Strain}

The BETA-1 $\Delta \mathrm{ybbO} \Delta$ malT::37blh strain expressing UTR37-blh $h_{S R}$ on the genome was constructed by integrating a synthetic module expressing UTR37-blh $h_{S R}$ into a malT site in BETA-1 $\triangle$ ybbO. Similarly, the BETA- $1 \Delta y b b O \Delta$ malT:: Mraldh strain was created through the integration of a synthetic module expressing UTRM-raldh into the malT site in BETA-1 $\triangle \mathrm{ybbO}$. BETA-1 $\triangle \mathrm{ybbO} \Delta \mathrm{malT}:: 37 \mathrm{blh}::$ Mraldh was constructed by integrating a synthetic module coexpressing UTR37-blh $h_{S R}$ and UTRM-raldh into the malT site in BETA- $1 \Delta y$ bbO. The abovementioned genome integrations were performed by using the CRISPR/Cas9 genome-editing system. Linear DNA fragments containing 250-bp homology arm sequences were constructed by using overlapping PCR with gene-specific primers (Supplementary Materials Table S1). The guide RNA (gRNA) sequence was designed by using the CHOPCHOP program (https:/ / chopchop.cbu.uib.no/, accessed on 10 September 2020). The pgRNA_malT vector was constructed via PCR-mediated amplification of the pgRNA plasmid backbone with primers containing $20 \mathrm{bp}$ of the gRNA sequence. Genome-editing strains were selected via colony PCR. The full sequence of the edited site in BETA- $1 \triangle \mathrm{ybbO}$ was verified through Sanger sequencing of the isolated gDNA (Macrogen, Seoul, Korea).

\subsection{Reverse-Transcription PCR (RT-PCR)}

Total RNA was extracted from $E$. coli cells expressing the $b l h_{\mathrm{SR}}$, UTR-12blh, UTR$37 b l h$, UTR-46blh, raldh, UTRM-raldh, or UTRM-raldh genes, which were grown in the mid-exponential growth phase, using an easy-BLUE ${ }^{\mathrm{TM}}$ Total RNA Extraction Kit (Intron, Seoul, Korea). For reverse transcription-polymerase chain reaction (RT-PCR) analysis, cDNA was synthesized from the total RNA samples, using the ReverTra ${ }^{\mathrm{TM}}$ Ace qPCR RT Kit (Toyobo, Osaka, Japan). PCR products were then analyzed on a $1 \%(w / v)$ agarose gel. The RT-PCR conditions were as follows: denaturation at $95^{\circ} \mathrm{C}$ for $1 \mathrm{~min} ; 30$ cycles of denaturation at $95^{\circ} \mathrm{C}$ for $30 \mathrm{~s}$, annealing at $60^{\circ} \mathrm{C}$ for $30 \mathrm{~s}$, and extension at $72{ }^{\circ} \mathrm{C}$ for $20 \mathrm{~s}$. The $c y s G$ gene encoding siroheme synthase was used as a reference gene. The primers used for the RT-PCR are listed in Supplementary Materials Table S1. 


\subsection{SDS-PAGE and Western Blot Analysis}

To fuse the $6 \times$ His amino acid sequence into the N-terminus of the BlhSR and RALDH2 proteins, the $b l h_{\mathrm{SR}}$ and raldh genes were cloned into the pET21 $\alpha(+)$ plasmid to construct pET21-blhSR and pET21-raldh, respectively. E. coli BL21 (DE3) harboring pET21 $\alpha(+)$, pET21-blhSR, or pET21-raldh was grown to an $\mathrm{OD}_{600}$ of $0.6-0.8$, then $1 \mathrm{mM}$ of isopropyl $\beta$-D-thiogalactopyranoside (IPTG) was added to the culture medium. Three hours after induction, the cells were harvested, washed twice with $50 \mathrm{mM}$ Tris- $\mathrm{HCl}$ buffer ( $\mathrm{pH}$ 6.8), and disrupted via sonication. The crude protein extracts were separated on a $12 \%$ $(w / v)$ SDS-PAGE gel. The gels were subsequently stained with Coomassie Brilliant Blue to visualize the protein bands. For Western blot analysis, the separated protein bands on the gels were transferred to a PVDF membrane, using Trans-Blot SD semi-dry (BioRad, Hercules, MA, USA) for $1 \mathrm{~h}$, at $25 \mathrm{~V}$. The blot was blocked with Tris-buffered saline with Tween 20 (TBST) containing $5 \%(w / v)$ skim milk for $2 \mathrm{~h}$ and washed three times with TBST, at $25^{\circ} \mathrm{C}$. SuperSinalTM West Pico PLUS Chemiluminescent substrate solution (Thermo Fisher Scientific, Waltham, MA, USA) was added for the immunodetection of $6 \times$ His-tagged BlhSR and RALDH2 on the membrane.

\subsection{Bioreactor Fermentation}

Batch fermentation was carried out in a $5 \mathrm{~L}$ BioFlo 320 bioreactor (Eppendorf, Hamburg, Germany) containing $1.5 \mathrm{~L}$ of TB medium (supplemented with $20 \mathrm{~g} / \mathrm{L}$ glycerol and $50 \mathrm{ug} / \mathrm{mL}$ chloramphenicol) under different conditions: culture temperature $(20,30$, and $\left.37^{\circ} \mathrm{C}\right)$, culture $\mathrm{pH}$ values $(6.0,6.5$, and 7.0$)$ and dissolved oxygen (DO) levels $(>10 \%, 30 \%$, and $50 \%$ ). The $\mathrm{pH}$ was maintained at a preset value through the automatic addition of $24 \%$ $(v / v) \mathrm{NH}_{4} \mathrm{OH}$ and $2 \mathrm{~N} \mathrm{HCl}$. The $\mathrm{DO}$ level was controlled by increasing the agitation rate from 200 to $600 \mathrm{rpm}$ and by supplying air and pure $\mathrm{O}_{2}$ gas. Cell growth was monitored at $600 \mathrm{~nm}\left(\mathrm{OD}_{600}\right)$, using a SpectraMax Plus384 spectrophotometer (Molecular Devices, San Jose, CA, USA).

\subsection{Extraction of Retinoids}

Retinoid-producing cells were harvested and extracted with $15 \mathrm{~mL}$ of acetone until all visible colors were extracted. To the acetone extract, $15 \mathrm{~mL}$ of $5 \mathrm{~N} \mathrm{NaCl}$ solution was added, and then the $\mathrm{pH}$ of the mixed solution was adjusted to 2.0 by adding $85 \%$ phosphoric acid (Sigma-Aldrich, Saint Louis, MO, USA). Next, an equal volume of hexane was added to the acidified mixed solution and mixed well. After centrifugation for $5 \mathrm{~min}$ at $3800 \mathrm{rpm}$, the upper solvent layer, which contained the retinoids, was collected and dehydrated over anhydrous sodium sulfate. The solution was then completely dried in a Genevac EZ2 centrifugal evaporator (SP Industries, Warminster, PA, USA). The dried residue was resuspended in $1 \mathrm{~mL}$ acetone and stored at $-20^{\circ} \mathrm{C}$, in the dark, until analysis.

\subsection{Extract Analysis Using HPLC and Mass Spectrometry (MS)}

A $5 \mu \mathrm{L}$ aliquot of the organic extract was injected into an Agilent 1260 high-performance liquid chromatography (HPLC) system (Agilent Technologies, Santa Clara, CA, USA) equipped with a photodiode array detector (Agilent Technologies) and a Poroshell 120 ECC18 column $(2.1 \times 50 \mathrm{~mm}, 2.7 \mu \mathrm{m}$; Agilent Technologies). The column temperature was maintained at $23{ }^{\circ} \mathrm{C}$, while the flow rate was maintained at $0.4 \mathrm{~mL} / \mathrm{min}$. Two mobile-phase systems were used for gradient elution: mobile phase A (methanol, acetonitrile, and acetic acid, 70.0:30.0:0.1, $v / v$ ) and mobile phase B (acetonitrile, methanol, water, isopropanol, and acetic acid, 60.0:20.0:19.0:5.0:0.1, $v / v$ ). The linear gradient was generated as follows: minutes $0-5,100 \%$ B; minutes $5-6,100 \%$ B to $100 \%$ A; minutes $6-28,100 \%$ A; minutes $28-29,100 \%$ A to $100 \%$ B; and minutes $29-35,100 \%$ B. The mass fragmentation spectrum of retinoic acid was monitored in positive mode on an LC-MS 6150 quadrupole system (Agilent Technologies) equipped with an atmospheric-pressure chemical ionization interface. The MS conditions used were described in our previous study [11]. 


\section{Results}

\subsection{Expression of Retinoic Acid Pathway Enzymes}

As a precursor-producing strain, the E. coli BETA-1 strain (unpublished) was used to construct the retinoic acid pathway. The BETA-1 strain has an engineered expression system for both the isopentenyl diphosphate and $\beta$-carotene biosynthetic pathways. Heterologous expression of two key retinoic acid pathway genes $\left(b h_{S R}\right.$ from $S$. ruber and raldh $h_{H S}$ from the Hep3B cell line) was investigated in two E. coli strains. When the $b l h_{S R}$ and $r a l d h_{H S}$ genes were induced through the $6 \times$ His tagging system [pET21 $\alpha(+)$ plasmid] in E. coli BL21 (DE3), one band corresponding to each gene was detected during immunoblotting (Figure 2A). The expected protein size ( $34.7 \mathrm{kDa}$ of $b l h_{S R}$ and $56.8 \mathrm{kDa}$ of $\left.r a l d h_{H S}\right)$ and one band of each gene indicated that $b l h_{S R}$ and $r a l d h_{H S}$ were expressed without protein degradation in the heterologous host $E$. coli. In addition, the mRNA transcription of each gene in the mid-log (at $36 \mathrm{~h}$ culture) and stationary growth (at $48 \mathrm{~h}$ culture) phases of the BETA-1 strain was confirmed via RT-PCR analysis (Figure 2B).

(A)

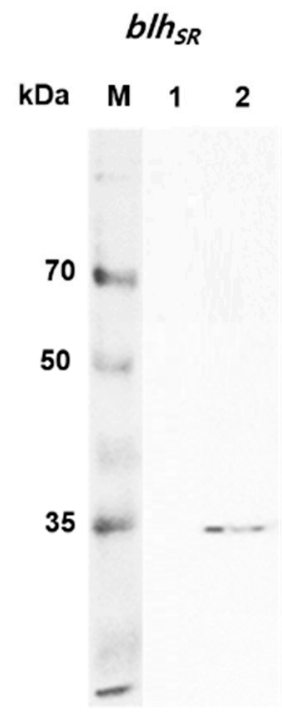

raldh $_{H S}$

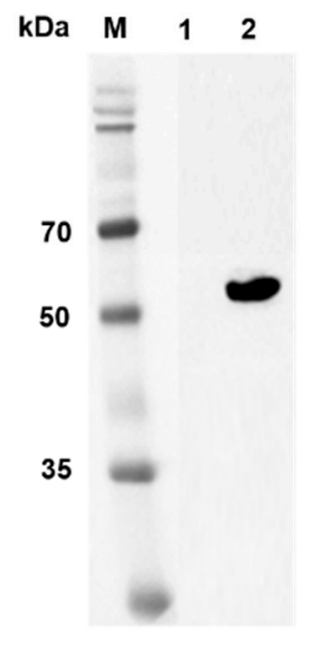

(B)

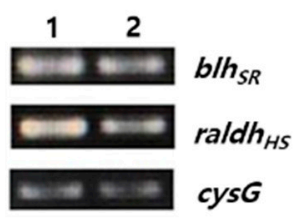

Figure 2. Western blot analysis and mRNA transcription of $b l h_{S R}$ and $r a l d h_{H S}$ genes. (A) Western blot analysis of the protein expression of $b l h_{S R}(\mathbf{l e f t})$ and raldh $_{H S}$ (right) in the E. coli BL21 (DE3) strain. Lane 1 in each panel indicates the total extracted proteins from BL21 (DE3)/pET21 $\alpha(+)$ while lane 2 indicates the total extracted proteins from BL21 (DE3)/pET21-blhSR (left), and BL21 (DE3)/pET21raldh (right). (B) Total RNA was isolated from the E. coli BETA-1 strain in the (1) mid-log and (2) stationary growth phases, and then the transcript levels of $b h_{S R}$ and raldh $_{H S}$ were analyzed via RT-PCR. The $c y s G$ gene was used as the reference gene.

\subsection{Construction of Retinoic Acid Biosynthetic Pathway in the E. coli BETA-1 Strain}

To reconstruct the retinoic acid pathway in the BETA-1 strain, the $b l h_{S R}$ and raldh $h_{H S}$ genes were made modular and assembled into the plasmid pSTVM2, constructing pSTVM2blh-radlh (Table 1). After the strain BETA-1/pSTVM2-blh-radlh (Figure 3A) was constructed, the acetone extract of the BETA-1/pSTVM2-blh-radlh grown in $100 \mathrm{~mL}$ flasks was analyzed together with the extracts of two control strains (BETA-1/pSTVM2 and BETA-1/pSTVM2-blh), using HPLC. One new peak (peak 1 in Figure 3B) in the extract of BETA-1/pSTVM2-blh-radlh was detected at the same retention time as that of the retinoic acid standard, within the same UV/Vis spectrum (Figure 3C). LC-MS analysis revealed that peak 1 in the extract of the BETA-1/pSTVM2-blh-radlh extract corresponded to a similar molecular fragment pattern and the same parent ion of $m / z 301.2[\mathrm{M}+\mathrm{H}]^{+}$as that of a retinoic acid standard (Figure 3D). Collectively, the $b l h_{S R}$ and $r a l d h_{H S}$ genes were functionally expressed in the BETA-1/pSTVM-blh-raldh strain, generating retinoic acid 
$(0.52 \pm 0.10 \mathrm{mg} / \mathrm{L})$ from $\beta$-carotene. Notably, the presence of retinol (peak 2$)$ and retinal (peak 3) in the extract of BETA-1/pSTVM2-blh was the same as that in our previous study [11].

(A)

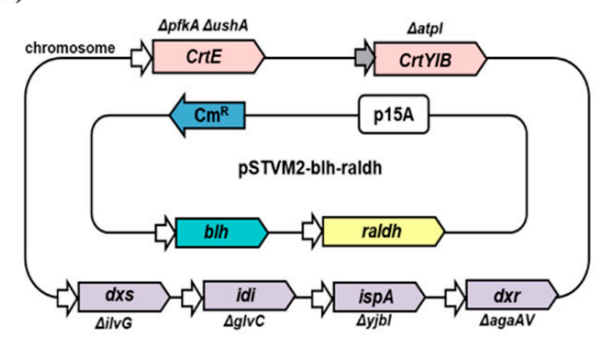

(C)
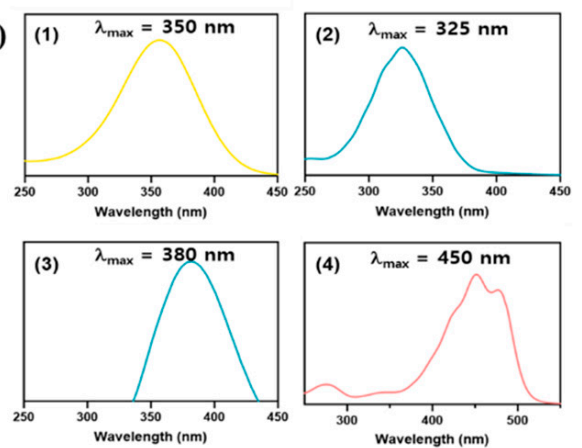

(B)

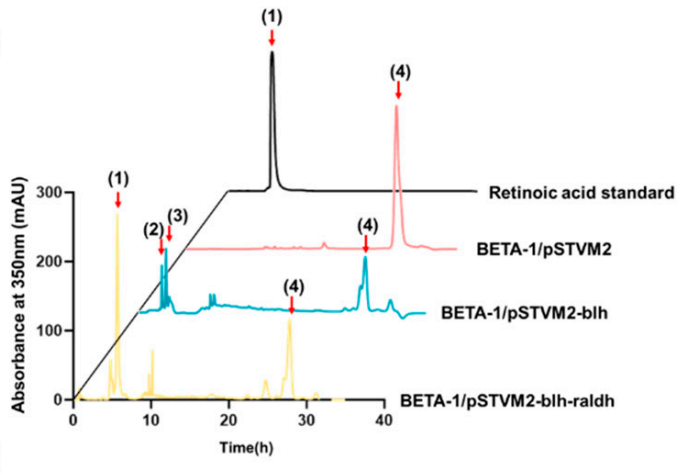

(D)
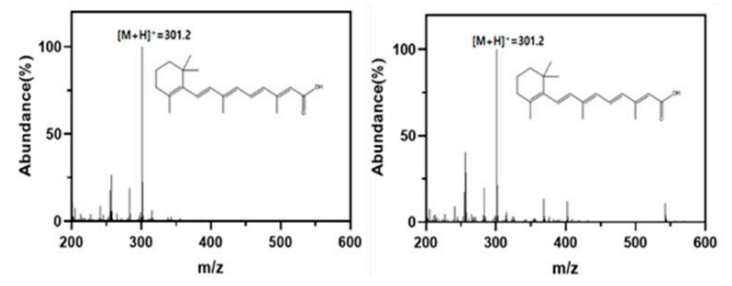

Figure 3. Reconstruction of the retinoic acid pathway and retinoid profiles in E. coli. (A) Schematic description of the metabolically engineered BETA-1 strain harboring the pSTVM2-blh-raldh plasmid expressing the Blh and ALDH1A2 enzymes for the biosynthesis of retinoic acid. (B) HPLC analysis of commercial standard retinoic acid and retinoid extracts from three recombinant $E$. coli strains. Peak 1 corresponds to retinoic acid; peak 2, retinol; peak 3, retinal; peak 4, $\beta$-carotene. (C) UV/Vis spectrum analysis of compounds corresponding to peaks 1-4 in the HPLC chromatogram. (D) LC-mass spectrometry analysis of a retinoic acid standard (left) and retinoic acid extracted from E. coli (right).

\subsection{Enhanced Retinoic Acid Production through Deletion of the ybbO Gene in the BETA-1 Strain}

It has been reported that endogenous aldehyde reductases, such as $y b b O$ in E. coli, showed unexpected activity similar to retinol reductase, an enzyme that converts retinal to retinol [9]. Therefore, the production of retinoic acid in BETA-1/pSTVM2-blh-radlh might be enhanced by limiting the conversion of retinal to retinol by suppressing endogenous aldehyde reductase activity. As a proof of this hypothesis, the $y b b O$ gene was deleted in the genome of the BETA-1 strain, creating the BETA-1 $\triangle \mathrm{ybbO}$ strain (named as RA1, Figure $4 \mathrm{~A}$ ). Quantitative analysis of acetone extracts of the strain RA1/pSTVM2-blh-radlh and the control strain BETA-1/pSTVM2-blh-radlh revealed that the RA1/pSTVM2-blh-radlh strain produced $1.43 \pm 0.06 \mathrm{mg} / \mathrm{L}$ of retinoic acid, which was 2.4 times higher than what the BETA-1/pSTVM2-blh-radlh strain produced $(0.59 \pm 0.06 \mathrm{mg} / \mathrm{L})$. No presence of retinal and retinol was observed in both strains, indicating that retinal was completely converted into retinoic acid. The increased titer of retinoic acid in the RA1/pSTVM2-blh-radlh strain can be explained by the fact that more retinal could be transformed into retinoic acid (Figure 1) in that strain. This is supported by the experiment of the two blh-expressing strains, where higher retinal $(0.47 \pm 0.1 \mathrm{mg} / \mathrm{L})$ and lower retinol $(0.25 \pm 0.05 \mathrm{mg} / \mathrm{L})$ titers were measured in the RA1/pSTVM2-blh strain in comparison with titers of retinal $(0.14 \pm 0.06 \mathrm{mg} / \mathrm{L})$ and retinol $(0.37 \pm 0.06 \mathrm{mg} / \mathrm{L})$ in the control BETA-1/pSTVM2-blh strain. 
(A)

\begin{tabular}{cl}
\hline RA strain & Combination (strain + plasmid) \\
\hline 1 & BETA-1 $\triangle y b b O$ \\
2 & BETA-1 $\triangle y b b O+$ pSTVM2-37blh-Mraldh \\
3 & BETA-1 $\triangle$ ybbO $\triangle$ malT::37blh \\
4 & BETA-1 $\triangle$ ybbO $\triangle$ malT::37blh + pSTVM2-Mraldh \\
5 & BETA-1 $\triangle$ ybbO $\triangle$ malT::37blh + pSTVM2-37blh-Mraldh \\
6 & BETA-1 $\triangle$ ybbO $\triangle$ malT::Mraldh \\
7 & BETA-1 $\triangle$ ybbO $\triangle$ malT::Mraldh + pSTVM2-37blh \\
8 & BETA-1 $\triangle$ ybbO $\triangle$ malT::Mraldh + pSTVM2-37blh-Mraldh \\
9 & BETA-1 $\triangle$ ybbO $\triangle$ malT::37blh::Mraldh \\
10 & BETA-1 $\triangle$ ybbO $\triangle$ malT::37blh::Mraldh + pSTVM2-37blh-Mraldh \\
\hline
\end{tabular}

(B)

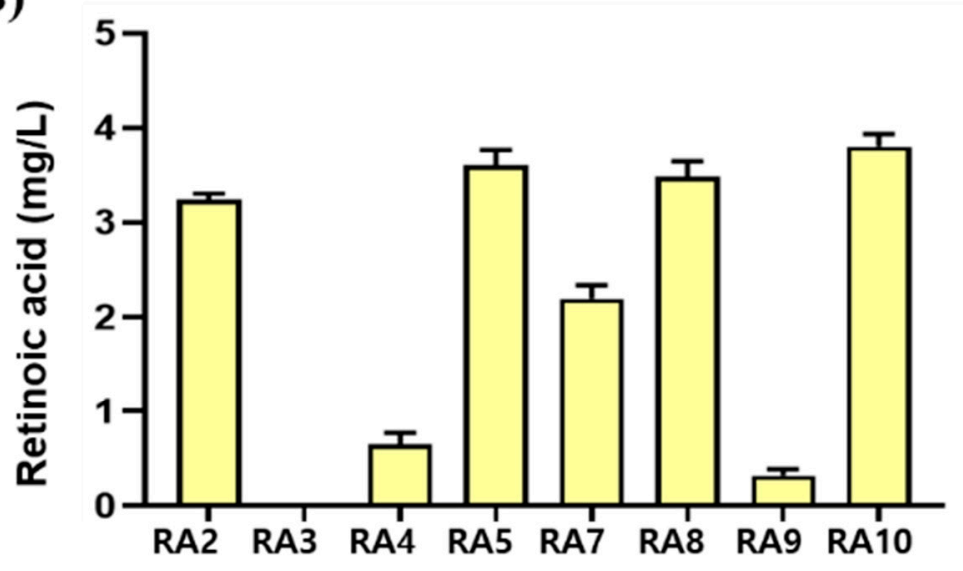

(C)

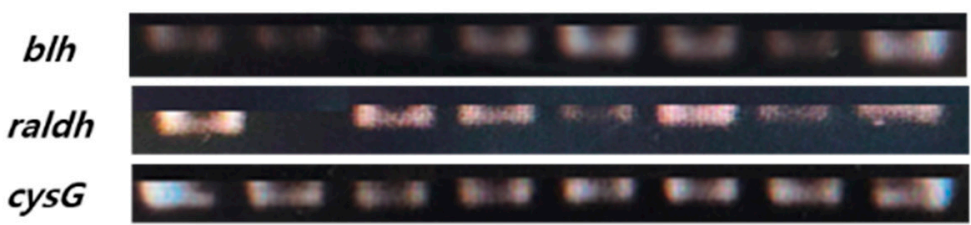

Figure 4. Retinoic acid production and mRNA expression level of the UTR37-blh ${ }_{S R}$ and UTRM-raldh genes in retinoic acid-producing strains. (A) List of strains constructed through genome editing and transforming plasmids into the genome-edited strains. (B) Retinoic acid production from eight metabolically engineered strains grown in flask cultures. (C) mRNA expression level of UTR37-blh ${ }_{S R}$ and UTRM-raldh genes in ten strains grown in flask cultures. The cys G gene, encoding siroheme synthase, was used as a reference gene.

\subsection{Transcription Control Engineering of blh $h_{S R}$ and raldh $h_{H S}$ Genes for Improving Retinoic Acid Production}

As a strategy for enhancing retinoic acid production, the mRNA-stabilizing region (mRS) engineering approach [11] was adopted to increase the expression of $b l h_{S R}$ and $r a l d h_{H S}$. Three previously studied synthetic sequences (UTR12, UTR37, and UTR46) [11] for regulating the expression of the $b l h_{S R}$ gene were assembled with raldh $h_{H S}$ into pSTVM2, constructing three retinoic acid-producing synthetic mRS-blh-raldh expression vectors: pSTVM2-12blhraldh, pSTVM2-37blh-raldh, and pSTVM2-46blh-raldh. Quantitative analysis of the four strains (RA1/pSTVM2-12blh-raldh, RA1/pSTVM2-37blh-raldh, RA1/pSTVM2-46blh-raldh, and RA1/pSTVM2-blh-raldh as a control) revealed that the RA1/pSTVM2-37blh-raldh strain produced the highest amount of retinoic acid $(2.63 \pm 0.14 \mathrm{mg} / \mathrm{L})$ among them. Similar to the design of mRS for $b l h_{S R}$, two mRS synthetic sequences (UTRH and UTRM for high and moderate expression, respectively) for raldh $h_{H S}$, were designed and assembled with 
UTR37-blh or blh into pSTVM2, resulting in two synthetic mRS-blh-mRS-raldh expression vectors (pSTVM2-37blh-Hraldh and pSTVM2-37blh-Mraldh) and two synthetic blh-mRSraldh expression vectors (pSTVM2-blh-Hraldh and pSTVM2-blh-Mraldh). Quantitative analysis of the four strains (RA1/pSTVM2-37blh-Hraldh, RA1/pSTVM2-37blh-Mraldh, pSTVM2-blh-Hraldh, and pSTVM2-blh-Mraldh) revealed that the RA1/pSTVM2-37blhMraldh strain produced the highest amount of retinoic acid $(3.46 \pm 0.16 \mathrm{mg} / \mathrm{L})$, which was 2.4 times higher than $1.43 \pm 0.07 \mathrm{mg} / \mathrm{L}$ in the non-mRS-engineered RA1/pSTVM2-blhraldh, 2.0 times higher than $1.71 \pm 0.10 \mathrm{~g} / \mathrm{L}$ in the mRS-raldh engineered RA1/pSTVM2blh-Mraldh, and 1.3 times higher than $2.63 \pm 0.14 \mathrm{mg} / \mathrm{L}$ in the mRS-blh engineered RA1/pSTVM2-37blh-raldh.

3.5. Construction and Expression of Retinoic Acid Biosynthetic Pathway Genes on the Genome of RA1 Strain

To integrate the retinoic acid pathway genes in the RA1 strain, two synthetic modules expressing each individual gene in UTR37-blh and UTRM-raldh and a synthetic module co-expressing two genes in UTR37-blh and UTRM-raldh were integrated into the malT site of the RA1 strain, using the CRISPR/Cas9 system (Figure 4A). The three genome-edited strains were BETA- $1 \Delta \mathrm{ybbO} \Delta$ malT::37blh (RA3), BETA-1 $\Delta$ ybbO $\Delta$ malT::Mraldh (RA6), and BETA-1 $\Delta y$ bbO $\Delta$ malT::37blh::Mraldh (RA9). To compare retinoic acid production in the three strains, the genome-edited RA3 strain was transformed with pSTVM2-Mraldh and pSTVM2-37blh-Mraldh, resulting in the RA3/pSTVM2-Mraldh (RA4) and RA3/pSTVM237blh-Mraldh (RA5) strains, respectively. Similarly, two strains, RA7 (RA6/pSTVM2-37blh) and RA8 (RA6/pSTVM2-37blh-Mraldh), were constructed from the genome-edited RA6 strain, and the RA10 (RA9/pSTVM2-37blh-Mraldh) strain was created from the genomeedited RA9 strain by transforming with the corresponding plasmids. When the retinoic acid titer was compared between the RA2 strain, where UTR37-blh and UTRM-raldh were expressed on a multi-copy plasmid system, and the RA9 strain, where UTR37-blh and UTRMraldh were expressed on the genome system, the retinoic acid titer $(0.32 \pm 0.05 \mathrm{mg} / \mathrm{L})$ of RA9 strain was approximately 7 times less than $3.24 \pm 0.05 \mathrm{mg} / \mathrm{L}$ of retinoic acid in the RA2 strain (Figure 4B). The difference of retinoic acid titer in the RA2 and RA9 strains may be due to the different expression levels of UTR37-blh and UTRM-raldh genes in RA2 and RA9. The mRNA levels of UTR37-blh and UTRM-raldh in RA2 were about two-fold higher than that in RA9 (Figure 4C). The highest amount of retinoic acid at $3.80 \pm 0.11 \mathrm{mg} / \mathrm{L}$ was produced in the RA10 strain grown in flask culture.

\subsection{Bioreactor Study of Retinoic Acid-Producing Strains}

To investigate the effect of culture conditions on retinoic acid production, the RA10 strain was grown in a bioreactor containing TB medium under different culture conditions (temperature, $\mathrm{pH}$, and $\mathrm{DO}$ levels). When the RA10 strain was grown at temperatures of 20, 30 , and $37^{\circ} \mathrm{C}$, at $\mathrm{pH} 7.0$, and a DO of $30 \%$, retinoic acid production was $3.92 \pm 1.25 \mathrm{mg} / \mathrm{L}$, $7.35 \pm 0.28 \mathrm{mg} / \mathrm{L}$, and $7.82 \pm 0.35 \mathrm{mg} / \mathrm{L}$, respectively. The final cell concentration at both 30 and $37^{\circ} \mathrm{C}$ was similar but decreased by approximately $45 \%$ at $20^{\circ} \mathrm{C}$ (Figure $5 \mathrm{~A}$ ). When the RA10 strain was grown at $\mathrm{pH}$ values of $6.0,6.5$, and 7.0 at $37^{\circ} \mathrm{C}$ and a $\mathrm{DO}$ of $30 \%$, retinoic acid production was $4.80 \pm 1.32 \mathrm{mg} / \mathrm{L}, 6.30 \pm 0.68 \mathrm{mg} / \mathrm{L}$, and $7.82 \pm 0.35 \mathrm{mg} / \mathrm{L}$, respectively. The final cell concentrations were similar at all $\mathrm{pH}$ values (Figure 5B). When the RA10 strain was grown at a $\mathrm{DO}$ of $10 \%, 30 \%$, and $50 \%$ at $\mathrm{pH} 7.0$ and $37^{\circ} \mathrm{C}$, retinoic acid production was $2.10 \pm 0.49 \mathrm{mg} / \mathrm{L}, 7.70 \pm 0.18 \mathrm{mg} / \mathrm{L}$, and $8.20 \pm 0.05 \mathrm{mg} / \mathrm{L}$, respectively. The final cell concentrations at both $50 \%$ and $30 \%$ DO were similar, but significantly reduced to $25 \%$ at $10 \%$ DO (Figure $5 \mathrm{C}$ ). The decreased cell growth at $10 \% \mathrm{DO}$ may be due to the high accumulation of acetic acid in the medium caused by the activated fermentative metabolism, triggering lower oxygen availability. Under all tested conditions, $20 \mathrm{~g} / \mathrm{L}$ glycerol was completely consumed, and acetic acid was produced up to $5.10 \pm 0.21 \mathrm{~g} / \mathrm{L}$ (Figure $5 \mathrm{~B}, \mathrm{C}$ ). Based on a retinoic acid titer (mg-retinoic acid/L) and a conversion yield (mg-retinoic acid/g-glycerol), $37^{\circ} \mathrm{C}, \mathrm{pH} 7.0$, and $50 \%$ DO were optimum conditions to produce retinoic acid in the RA10 strain. 
(A) Temperature
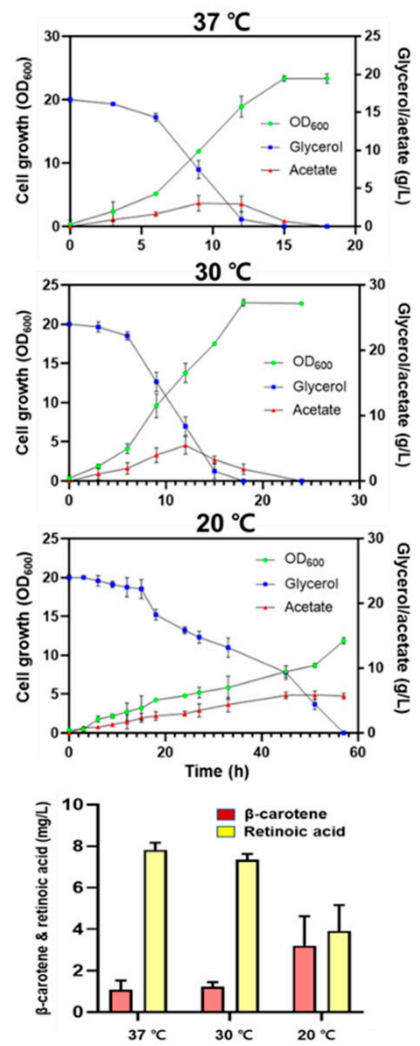

(B) $\mathrm{pH}$

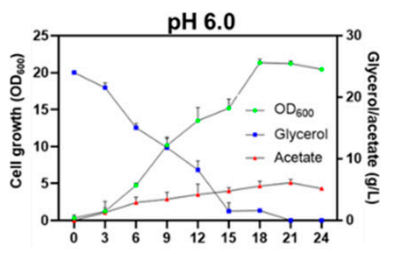

pH 6.5

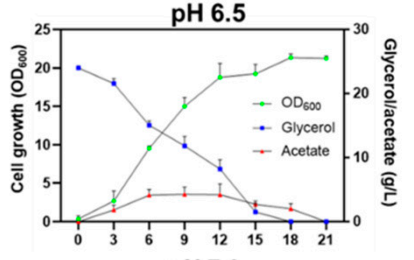

$\mathrm{pH} 7.0$
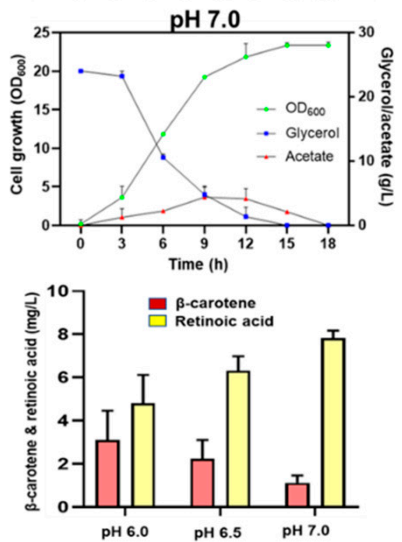

(C) DO
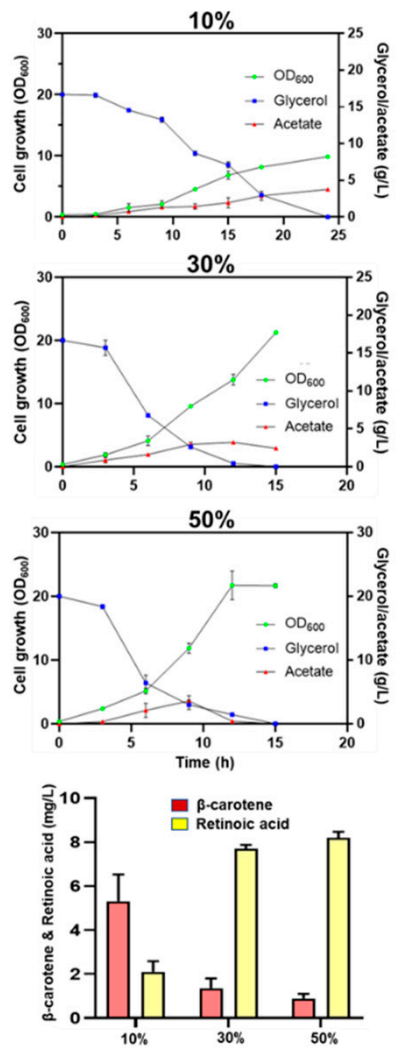

Figure 5. Batch fermentation of the RA10 strain under different culture conditions. (A) Effect of temperature (20, 30, and $\left.37^{\circ} \mathrm{C}\right)$ on cell growth at $\mathrm{pH} 7.0$ and a DO of $30 \%$. (B) Effect of $\mathrm{pH}(6.0,6.5$, and 7.0$)$ on cell growth at $37^{\circ} \mathrm{C}$ and a $\mathrm{DO}$ of $30 \%$, (C) Effect of DO $(10 \%, 30 \%$, and $50 \%)$ on cell growth at $\mathrm{pH} 7.0$ and $37^{\circ} \mathrm{C}$. Cell growth $\left(\mathrm{OD}_{600}\right)$ is represented as a green circle; glycerol concentration, a blue square; acetate concentration, a red triangle.

\section{Discussion}

The production of retinoids, including retinol and retinyl ester, from microbes has been successfully reported. To date, there are no reports on the microbial biosynthesis of retinoic acid. Recently, one study reported that retinoic acid could be produced from retinol in an in vitro system utilizing a bacterial aldehyde dehydrogenase [14]. Therefore, to construct a platform microbial strain for retinoic acid production, two genes $\left(b l h_{S R}\right.$ and rald $_{H S}$ ) encoding retinoic acid biosynthesis pathway enzymes, $\beta$-carotene $15,15^{\prime}$ oxygenase (Blh) [11] and retinaldehyde dehydrogenase 2 (RALDH2), were synthetically redesigned to be modularly expressed [15]. Co-expression of the $b l h_{S R}$ and $r a l d h_{H S}$ genes on the plasmid system in the BETA- 1 strain produced $0.59 \pm 0.06 \mathrm{mg} / \mathrm{L}$ of retinoic acid in flask cultivation (Figure 3). Notably, it has been thought that mammalian RALDHs did not show retinal activity in microbial hosts [14]. However, the rald $h_{H S}$ gene encoding mammalian RALDH2 from the Hep3B cell line was functionally transcribed (analyzed via RT-PCR) and translated (analyzed through Western blot) in a microbial host, E. coli (Figure 2). Retinoic acid was produced from retinal that was generated from $\beta$-carotene by Blh in the BETA-1 strain.

To increase the retinoic acid titer, three approaches were used: (1) deletion of the $y b b O$ gene encoding a promiscuous aldehyde reductase, (2) engineering of the $5^{\prime}$-UTR sequence of the $b l h_{S R}$ and $r a l d h_{H S}$ genes, and (3) optimization of culture conditions of retinoic acidproducing strains in a bioreactor. A 2.4-fold enhancement in retinoic acid production, from $0.59 \pm 0.06 \mathrm{mg} / \mathrm{L}$ to $1.43 \pm 0.06 \mathrm{mg} / \mathrm{L}$, was observed after the deletion of the $y b b O$ gene, which decreased retinoic acid titer through the reduction of retinal to retinol. The gene deletion effect was confirmed by observing a higher production $(0.47 \pm 0.1 \mathrm{mg} / \mathrm{L})$ 
of the retinoic acid precursor retinal in the BETA- $1 \triangle y b b O$ strain expressing only Blh than that $(0.14 \pm 0.06 \mathrm{mg} / \mathrm{L})$ of the BETA- 1 strain expressing only Blh. Therefore, limiting the activity of promiscuous aldehyde reductases is crucial for the production of retinoic acid in heterologous microbial strains. Engineering of the $5^{\prime}$-UTR sequence to increase the expression level of pathway enzymes, especially in heterologous hosts, has been successfully exploited in E. coli $[11,16,17]$ and yeasts [18]. Further, $5^{\prime}$-UTR engineering was successfully applied to the $b l h_{S R}$ and $r a l d h_{H S}$ genes of the retinoic acid biosynthesis pathway, consequently increasing the retinoic acid yield from $1.43 \pm 0.06 \mathrm{mg} / \mathrm{L}$ to $3.46 \pm 0.16 \mathrm{mg} / \mathrm{L}$ in flask cultivation. Finally, optimized culture conditions $\left(37^{\circ} \mathrm{C}\right.$, pH 7.0, and $50 \% \mathrm{DO}$ ) enhanced retinoic acid production of up to $8.20 \pm 0.05 \mathrm{mg} / \mathrm{L}$ in a bioreactor (Figure 5).

Even though the retinoic acid pathway genes were co-expressed on the genome of the BETA- $1 \Delta \mathrm{ybbO}$ strain, the retinoic acid titer was 10 times less $(0.32 \pm 0.05 \mathrm{mg} / \mathrm{L})$ than that obtained via co-expression on a plasmid in the BETA- $1 \Delta y b b O$ strain (Figure 4$)$. This suggests that the optimization of the expression levels of retinoic acid pathway genes is crucial, and thus should be regarded as a target for the increased production of retinoic acid. In addition, as a precursor, $\beta$-carotene accumulated without being converted into retinal, so the protein engineering of Blh is needed to have higher activity on $\beta$-carotene. Finally, as the construction and culture of retinoic acid-producing strains is at an early stage in the development of the microbial processes for retinoic acid production, further optimization of the fermentation operations (such as fed-batch cultivation), media, and intensive strain improvement should increase the current titer of retinoic acid in E. coli.

Supplementary Materials: The following are available online at https:/ / www.mdpi.com/article / 10.3390/microorganisms9071520/s1. Table S1: Primers used in this study.

Author Contributions: Conceptualization, P.C.L.; methodology, M.H. and P.C.L.; formal analysis, M.H.; writing — original draft preparation, M.H. and P.C.L.; writing—review and editing, M.H. and P.C.L.; visualization, M.H. and P.C.L.; supervision, P.C.L.; funding acquisition, P.C.L. All authors have read and agreed to the published version of the manuscript.

Funding: This research was supported by the National Research Foundation of Korea (grant numbers 2020R1A2C300889 and 2020M3A9I5037889) and by the Priority Research Centers Program through the National Research Foundation of Korea (grant number 2019R1A6A11051471).

Institutional Review Board Statement: Not applicable.

Informed Consent Statement: Not applicable.

Data Availability Statement: Not applicable.

Acknowledgments: The Hep3B cell line was a gift from Wook Kim (Ajou University, South Korea).

Conflicts of Interest: The authors declare no conflict of interest. The funders had no role in the study design; in the collection, analyses, or interpretation of data; in the writing of the manuscript; or in the decision to publish the results.

\section{References}

1. Clagett-Dame, M.; Knutson, D. Vitamin A in reproduction and development. Nutrients 2011, 3, 385-428. [CrossRef] [PubMed]

2. Mayo-Wilson, E.; Imdad, A.; Herzer, K.; Yakoob, M.Y.; Bhutta, Z.A. Vitamin A supplements for preventing mortality, illness, and blindness in children aged under 5: Systematic review and meta-analysis. BMJ 2011, 343, d5094. [CrossRef]

3. D'Ambrosio, D.N.; Clugston, R.D.; Blaner, W.S. Vitamin A metabolism: An update. Nutrients 2011, 3, 63-103. [CrossRef]

4. Temova Rakusa, Z.; Skufca, P.; Kristl, A.; Roskar, R. Retinoid stability and degradation kinetics in commercial cosmetic products. J. Cosmet Dermatol. 2020, 20, 2350-2358. [CrossRef] [PubMed]

5. Yang, J.; Wang, W.; Ooi, J.; Campos, L.S.; Lu, L.; Liu, P. Signalling Through Retinoic Acid Receptors is Required for Reprogramming of Both Mouse Embryonic Fibroblast Cells and Epiblast Stem Cells to Induced Pluripotent Stem Cells. Stem Cells 2015, 33, 1390-1404. [CrossRef] [PubMed]

6. Temova Rakuša Ž, Škufca, P.; Kristl, A.; Roškar, R. Quality control of retinoids in commercial cosmetic products. J. Cosmet Dermatol. 2021, 20, 1166-1175. [CrossRef] [PubMed]

7. Choi, B.H.; Kim, J.H.; Choi, S.Y.; Han, S.J.; Lee, P.C. Redesign and reconstruction of a mevalonate pathway and its application in terpene production in Escherichia coli. Bioresour. Technol. Rep. 2019, 7, 100291. [CrossRef] 
8. Parker, G.L.; Smith, L.K.; Baxendale, I.R. Development of the industrial synthesis of vitamin A. Tetrahedron 2016, 72, 1645-1652. [CrossRef]

9. Jang, H.J.; Ha, B.K.; Zhou, J.; Ahn, J.; Yoon, S.H.; Kim, S.W. Selective retinol production by modulating the composition of retinoids from metabolically engineered E. coli. Biotechnol. Bioeng. 2015, 112, 1604-1612. [CrossRef] [PubMed]

10. Jang, H.J.; Yoon, S.H.; Ryu, H.K.; Kim, J.H.; Wang, C.L.; Kim, J.Y.; Oh, D.K.; Kim, S.W. Retinoid production using metabolically engineered Escherichia coli with a two-phase culture system. Microb. Cell Fact. 2011, 10, 59. [CrossRef] [PubMed]

11. Choi, B.H.; Hwang, H.J.; Lee, J.E.; Oh, S.H.; Hwang, J.S.; Lee, B.Y.; Lee, P.C. Microbial Production of Retinyl Palmitate and Its Application as a Cosmeceutical. Antioxidants 2020, 9, 1130. [CrossRef] [PubMed]

12. Sun, L.; Kwak, S.; Jin, Y.S. Vitamin A Production by Engineered Saccharomyces cerevisiae from Xylose via Two-Phase in Situ Extraction. ACS Synth Biol. 2019, 8, 2131-2140. [CrossRef] [PubMed]

13. Mehrer, C.R.; Incha, M.R.; Politz, M.C.; Pfleger, B.F. Anaerobic production of medium-chain fatty alcohols via a beta-reduction pathway. Metab. Eng. 2018, 48, 63-71. [CrossRef] [PubMed]

14. Hong, S.H.; Ngo, H.P.; Nam, H.K.; Kim, K.R.; Kang, L.W.; Oh, D.K. Alternative Biotransformation of Retinal to Retinoic Acid or Retinol by an Aldehyde Dehydrogenase from Bacillus cereus. Appl. Environ. Microbiol. 2016, 82, 3940-3946. [CrossRef] [PubMed]

15. Kim, S.H.; Lee, P.C. Functional expression and extension of staphylococcal staphyloxanthin biosynthetic pathway in Escherichia coli. J. Biol. Chem. 2012, 287, 21575-21583. [CrossRef]

16. Moon, J.H.; Lee, K.; Lee, J.H.; Lee, P.C. Redesign and reconstruction of a steviol-biosynthetic pathway for enhanced production of steviol in Escherichia coli. Microb. Cell Fact. 2020, 19, 20. [CrossRef] [PubMed]

17. Song, J.W.; Woo, J.M.; Jung, G.Y.; Bornscheuer, U.T.; Park, J.B. 3'-UTR engineering to improve soluble expression and fine-tuning of activity of cascade enzymes in Escherichia coli. Sci. Rep. 2016, 6, 29406. [CrossRef] [PubMed]

18. Ding, W.; Cheng, J.; Guo, D.; Mao, L.; Li, J.; Lu, L.; Zhang, Y.; Yang, J.; Jiang, H. Engineering the 5' UTR-Mediated Regulation of Protein Abundance in Yeast Using Nucleotide Sequence Activity Relationships. ACS Synth Biol. 2018, 7, 2709-2714. [CrossRef] [PubMed] 